der C-Linie. Aus der oben angefuhrten Tabelle ist ersichtlich, dass die Wasserstofflinien des Meteoriten auch in dem Luftspectrum vorkommen, also nicht unbedingt dem Meteoriten zugeschrieben werden müssen; nach Abzug der Wasserstoff-

Odessa, 1898 April 27. linien wird das Spectrum des Meteoriten mit dem des Kohlenoxyds fast identisch, was mit dem Ergebnisse von Vogel übereinstimmt.

\title{
Beobachtung der Bedeckung von $\alpha$ Scorpii (Antares) 1898 März 13
}

auf der k. k. Sternwarte $z$ u Prag.

\begin{tabular}{|c|c|c|c|c|c|c|c|}
\hline $\mathrm{Ph}$. & Sternz. Prag & M. Z. Greenw. & Instr. & Vgr. & Oeffn. & Beobacht. & Bemerkungen \\
\hline E. h. & $\begin{array}{lll}15 & 22 & 53.98\end{array}$ & $14^{\mathrm{h}} 5^{8^{\mathrm{m}} 12^{\mathrm{s}} .45}$ & Steinh. & 152 & 162.6 & $\begin{array}{l}\text { Weinek } \\
\text { Oppolzer }\end{array}$ & $\begin{array}{l}\text { Sichere Beobachtung. Luft sehr unruhig und dunstig. } \\
\text { Mond tief. Stern tritt } 3^{\text {s.8 }} \text { vor seinem Verschwinden } \\
\text { auf die Mondscheibe } \\
\text { Sehr gut }\end{array}$ \\
\hline
\end{tabular}

A.d. \begin{tabular}{llll|lll||l|l|l|l|l|l|}
16 & 33 & 43.33 & 16 & 8 & 50.40
\end{tabular}

Uhrvergleichungen vor Eintritt und nach Austritt, sowie Zeitbestimmung in derselben Nacht erfolgten durch den I. Assistenten Herrn Dr. E. von Oppolzer. Die Uhrgänge wurden aus März Ia und 21 abgeleitet. Für die Iängendifferenz Prag - Greenwich wurde $-57^{m} 40^{5} 36^{*}$ ) angenommen.

Prag 1898 April 20.

\section{Weinek.}

"Siehe : Astronomische Beobachtungen an der k. k. Sternwarte zu Prag in den Jahren 1888, 1889, 1890 u. 1891*, Prag I893, S. 14.

Beobachtung des Cometen 1898 . . (Perrine Juni 14).

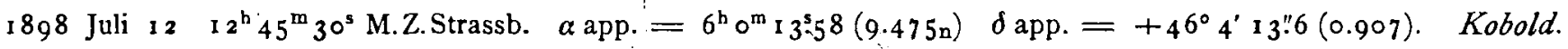

\section{Cometa $1898 \ldots$ (Coddington-Pauly).}

Colle mie osservazioni, in numero di sette; fra Giugno 14 e Luglio 3, ho corretto i primi elementi parabolici, che io aveva calcolato in basa alle osservazioni di Roma dei giorni

$$
\begin{aligned}
& T=\text { r } 898 \text { Sett. } 13.81843 \text { t. m. Berlino } \\
& \infty=232^{\circ} 57^{\prime} 59^{\prime \prime} 3 \\
& \text { - } \delta=735928.0 \text { × } 898.0 \\
& i=70 \text {. } 336.8 \\
& \log q=0.232 \times 40
\end{aligned}
$$

14, 18 e 22 Giugno. I nuovi elementi, che di pochissimo differiscono dai primi, rappresentano bene tutte le sette osservazioni. Essi sono i seguenti:

$$
\begin{aligned}
& x=[9.631924] r \cdot \operatorname{sen}\left(z+12^{\circ} 53^{\prime} 20^{\prime \prime} 5\right) \\
& y=[9.967346] r \cdot \operatorname{sen}(v+3412231.8) \\
& z=[9.990233] r \cdot \operatorname{sen}(v+2555954.5)
\end{aligned}
$$

Se si assume per unità l'intensità luminosa della cometa il dì della scoperta, quella dovrebbe essere 0.48 il 29 Sett.

Effemeride per I $^{\text {h }}$ di Berlino.

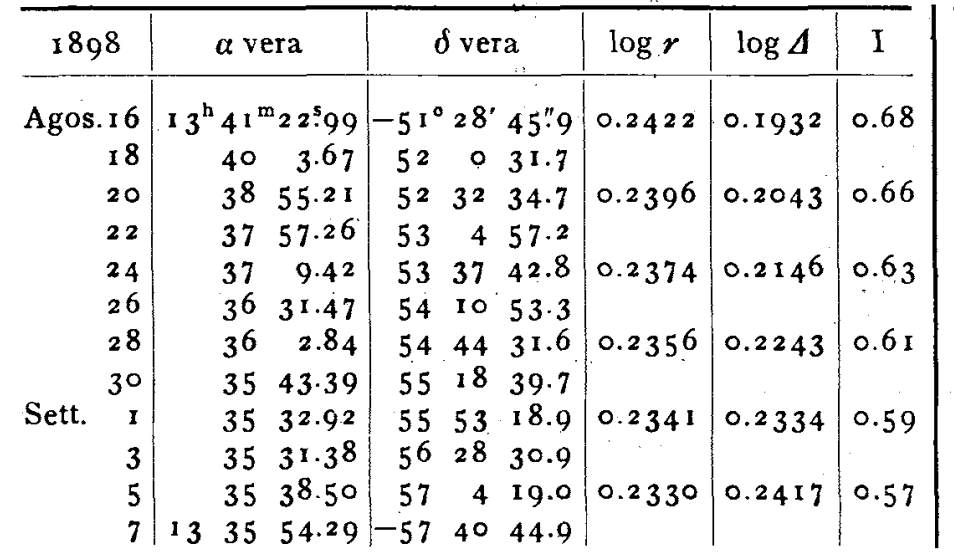

Frascati, 1898 Agosto 4 .

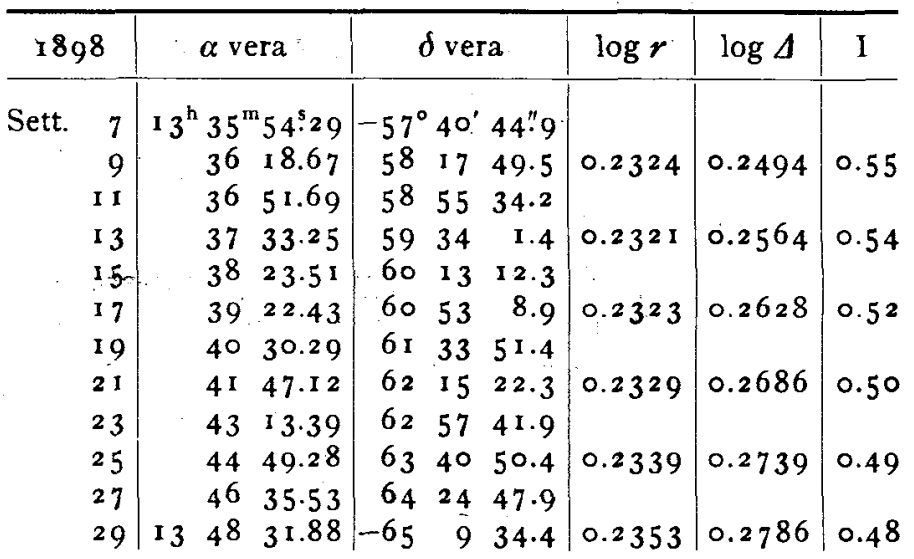

E. Millosevich. 